\title{
Telehealth: A Very Useful Tool That Enables and Improves Patient Access
}

\author{
Charles R. Doarn, MBA
}

Coffman et $\mathrm{al}^{1}$ address a significant challenge in American medicine in this issue of the journal. In their article, "Who Is Using Telehealth in Primary Care? Safety Net Clinics and Health Maintenance Organizations," they discuss the results of a survey conducted by the American Academy of Family Physicians and analyzed by the Robert Graham Center. ${ }^{1}$ This survey leads us to believe that there is a significant difference between family physicians who used and who did not use telehealth services in 2014, the year of the survey. This can be seen as a good indicator of how telehealth is being adopted and how it is not adopted within general medical practice in a small sample.

At the onset, we need to understand the terminology surrounding the use of technology for the remote delivery of health care. The terms telebealth and telemedicine are often used interchangeably. They are, however, different. Telemedicine has been around for a long time and has been defined in many ways by many individuals and organizations. ${ }^{2}$ Telehealth is a more inclusive term. In addition, even more terms have entered the lexicon in recent years, including virtual health, e-Health, m-Health, and, of course, terms such as telemonitoring. ${ }^{3} \mathrm{Re}-$ gardless of the word, a patient's health can be managed effectively using telehealth. Purcell et $\mathrm{al}^{4}$ conducted a systematic review of telemonitoring of patients with chronic cardiovascular disease.

From the Department of Family and Community Medicine, University of Cincinnati, Cincinnati, OH.

Funding: none.

Conflict of interest: none declared.

Corresponding author: Charles R. Doarn, MBA, Department of Family and Community Medicine, University of Cincinnati, 231 Albert Sabin Way, MSB\#4453B, Cincinnati, OH 45140-0582 (E-mail: charles.doarn@uc.edu).

\section{See Related Article on Page 432.}

Patients should have access to health care services in highly developed countries, and that access should not be limited by distance or geography. This is where telehealth can play a significant role. However, the adoption of telehealth across the landscape of American health care is fraught with many barriers and challenges, including access issues, education, legal issues, reimbursement, attitudes, geography, and a driving penchant to adopt technology. We must look at these barriers in many contexts. Whether telehealth or other new approaches to health care delivery are embraced may be driven by an individual's zip code. Not all 50 states have the same rules and regulations surrounding telehealth. The American Telemedicine Association recently completed an informative "gap" analysis of telemedicine coverage and reimbursement. ${ }^{5}$ This 2016 analysis provides a review of where each of the 50 states are with regard to these two important issues.

Primary care plays a central role in our health care system. With the predicted shortage of physicians across the United States and the world, we must think of new and effective ways of treating our patients, including changes in our education model or our practice model. ${ }^{6-8}$ In a recent article, Bashshur et $\mathrm{al}^{9}$ review the empirical evidence of telemedicine interventions in primary care. They reviewed $>2300$ articles on studies published from 2005 to 2015 , and only 86 met the inclusion criteria for their analysis. This review also indicated a significant variance in adoption and use; however, it was clear that patients found telemedicine to be more acceptable than did providers. Even though telemedicine and telehealth have become integral parts of primary care worldwide, the adoption of telehealth in the United States still faces challenges, including validation of technologies and methodologies.

If family medicine physicians have an awareness of and are not using telehealth, is it because of reimbursement or legal barriers such as liability and 
licensing? Or is something else preventing adoption? ${ }^{10}$ The very first line of the article by Coffman et $\mathrm{al}^{1}$ sets the stage for moving forward and provides the opening salvo for change. That is the continued, unabated advance in technologies we now take for granted. The rapid advancement of technologies such as smartphones and tablets and the continuous flow of apps, faster computing power, cloud storage, informatics, and sensors all point to an evolving business model. In addition to these innovations, federal laws and regulations, including the Patient Protection and Affordable Care Act and meaningful use, affect the adoption of new approaches to health care.

As Coffman et $\mathrm{al}^{1}$ state in their last sentence, there is ". . . a need for greater evidence of telehealth's benefits . . ."; we continue to conduct peer-reviewed research and collect data. We must continue down this path of making health care affordable for the entire system, not just 1 part of it. We must embrace innovation while ensuring patient safety and the satisfaction of all parties involved. Patients must be satisfied with their care, but providers should also be satisfied with the technology they are using to manage their patients.

The American Academy of Family Physicians study is an excellent start to understanding the barriers and challenges the primary care system faces in expanding the adoption of telehealth, regardless of physical address, IP address, or whatever label has been given to the practice location. I commend Coffman et $\mathrm{al}^{1}$ for conducting this study and look forward to future work in the application of telehealth in primary care.

\section{References}

1. Coffman M, Moore M, Jetty A, Klink K, Bazemore A. Who is using telehealth in primary care? Safety net clinics and health maintenance organizations. J AM Board Fam Med 2016;29:432-3.

2. Sood S, Jugoo S, Dooky R, et al. What is telemedicine?: 104 peer-reviewed perspectives and theoretical underpinnings. Telemed J E Health 2007;13: 573-90.

3. Haselkorn A, Coye MJ, Doarn CR. The future of remote health services: summary of an expert panel discussion. Telemed J E Health 2007;13:341-7.

4. Purcell R, McInnes S, Halcomb EJ. Telemonitoring can assist in managing cardiovascular disease in primary care: a systematic review of systematic reviews. BMC Fam Pract 2014;15:43.

5. American Telemedicine Association. Gap analysis. Available from: http://www.americantelemed.org/ docs/default-source/policy/2016_50-state-telehealthgaps-analysis-coverage-and-reimbursement.pdf. Accessed April 21, 2016.

6. Bodenheimer TS, Smith MD. Primary care: proposed solutions to the physician shortage without training more physicians. Health Aff (Millwood) 2013;32:1881-6.

7. Yee T, Boukus EL, Cross D, Samuel DI. Primary care workforce shortages: nurse practitioner scope-of-practice laws and payment policies. NIHCR research brief no. 13. February 2013. Available from: http://www.nihcr.org/pcp-workforcenps. Accessed June 1, 2016.

8. Auerbach DI, Chen PG, Friedberg MW, et al. Nurse-managed health centers and patient-centered medical homes could mitigate expected primary care physician shortage. Health Aff (Millwood) 2013;32: 1933-41.

9. Bashshur RL, Howell JD, Krupinski EA, Harms KM, Bashshur N, Doarn CR. The empirical foundations of telemedicine intervention in primary care. Telemed J E Health 2016;22:342-75.

10. Call VR, Erickson LD, Dailey NK, et al. Attitudes toward telemedicine in urban, rural, and highly rural communities. Telemed J E Health 2015;21:644-51. 